\title{
Transcatheter successful palliation of a newborn with ductal-dependent pulmonary circulation
}

\author{
Tamer Yoldaş ${ }^{1}$, Senem Özgür ${ }^{2}$, Vehbi Doğan¹, Özkan Kaya ${ }^{1}$, Utku Arman Örün², \\ Selmin Karademir ${ }^{3}$
}

1) Dr.Sami Ulus Maternity and Children Research and Training Hospital,Department of Pediatric Cardiology, Specialist Dr., Ankara, Turkey

2) Dr.Sami Ulus Maternity and Children Research and Training Hospital,Department of Pediatric Cardiology, Assoc. Dr., Ankara, Turkey

3) Dr.Sami Ulus Maternity and Children Research and Training Hospital,Department of Pediatric Cardiology, Prof. Dr., Ankara, Turkey

\begin{abstract}
We report a newborn who have congenital heart disease with duct-dependent pulmonary circulation and hypoplastic peripheral pulmonary arteries, was successfully palliated with ductal multiple stent implantation.
\end{abstract}

Key words: Pulmonary atresia, pulmonary hypoplasia, ductal stent implantation.

Yoldaş T., Özgür S., Doğan V., Kaya Ö., Örün U. A., Karademir S. Transcatheter successful palliation of a newborn with ductal-dependent pulmonary circulation. EJCM 2017; 05 (2): 34-36. Doi: 10.15511/ejcm.17.00234

Copyright $\mathbb{C} 2017$ Heart and Health Foundation of Turkey (TÜSAV). Published by Medikal Akademi.

This article is licensed by Medikal Akademi and TÜSAV under the terms of Creative Commons Attribution License. 


\section{Introduction}

Conventional management of neonates with ductaldependent pulmonary flow entails maintaining ductal patency using prostaglandin E1 infusion followed by surgical palliation with Blalock-Taussig shunt (B-T shunt). Nowadays, percutaneous transcatheter placement of a stent to maintain ductal patency has been used as an alternative method to provide a source of pulmonary blood flow. ${ }^{[1,2]}$ The potential advantages of ductal stenting include reduced procedure-related risks and improved distribution of pulmonary artery blood flow. ${ }^{[3]}$ Ductal stenting could be used as a bridge toward corrective surgery in neonates. ${ }^{[4]}$

Figure 1. Vertical, tortuous ductus with distal narrowing.

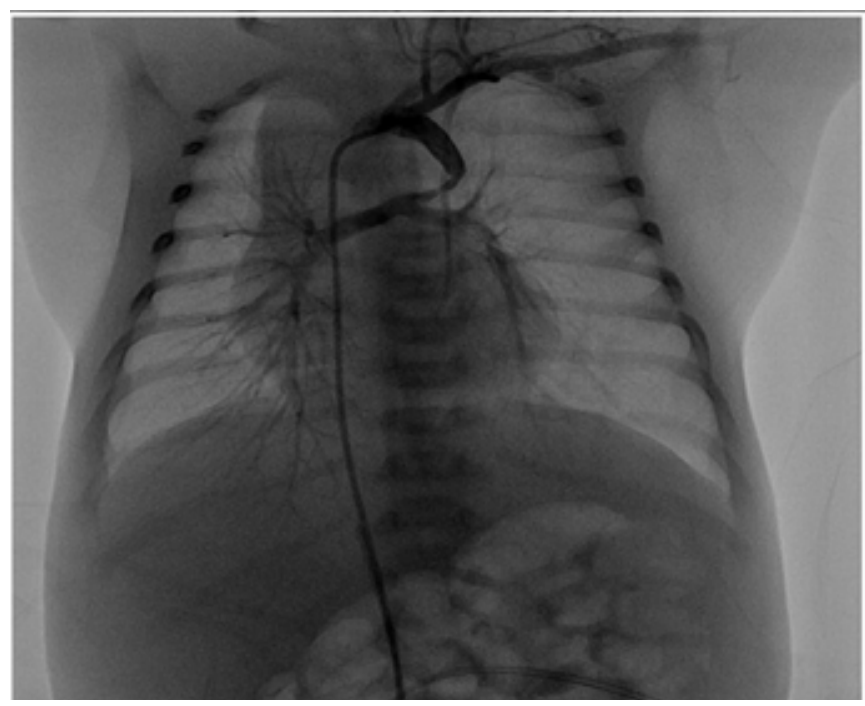

Figure 3. Second stent implantation

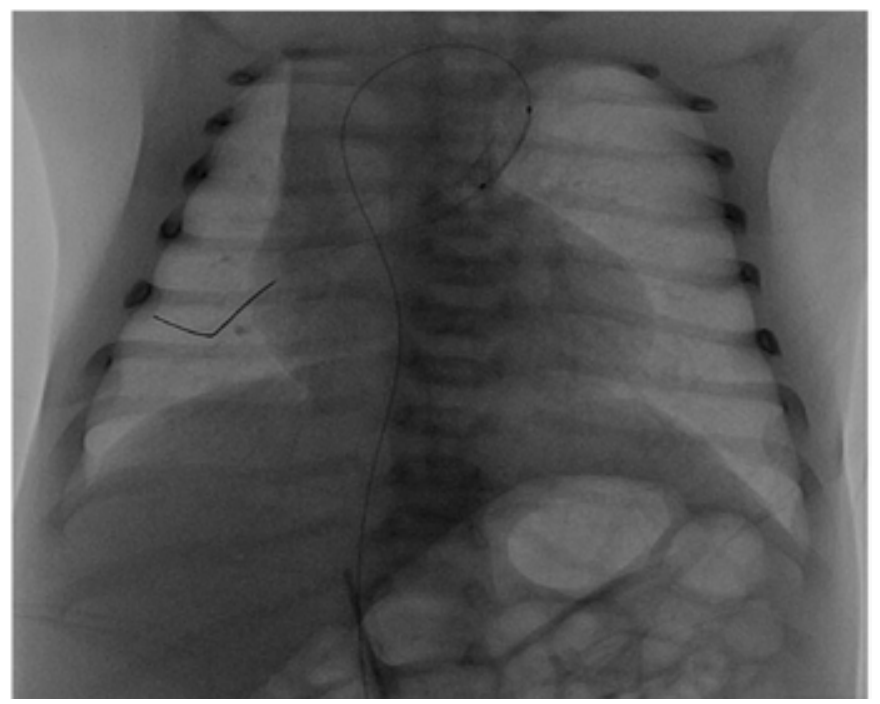

\section{Case Report}

A two-day-old boy was referred to our hospital for cardiac evaluation moderate to severe cyanosis (percutaneous oxygen saturation $60 \%$ ). Echocardiography showed, situs solitus, levocardia, concordant atrioventricular connection, large outlet ventricular septal defect, pulmonary atresia, hypoplastic pulmonary artery branches, right aortic arch and vertical arterial duct. Cardiac catheterization was performed via right femoral vein. Pulmonary artery branches were hypoplastic (right and left pulmonary artery $3 \mathrm{~mm}$ ) and supplied by a vertical, tortuous ductus with distal narrowing which arises from the inner curve of a right sided aortic

Figure 2. First stent implantation

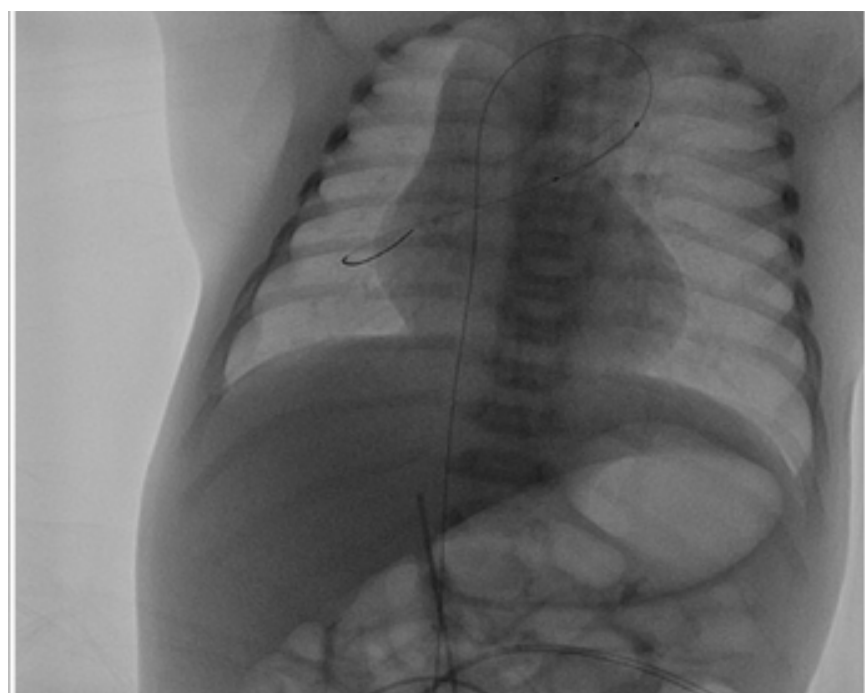

Figure 4. Critically stenotic aortic end of ductus arteriosus

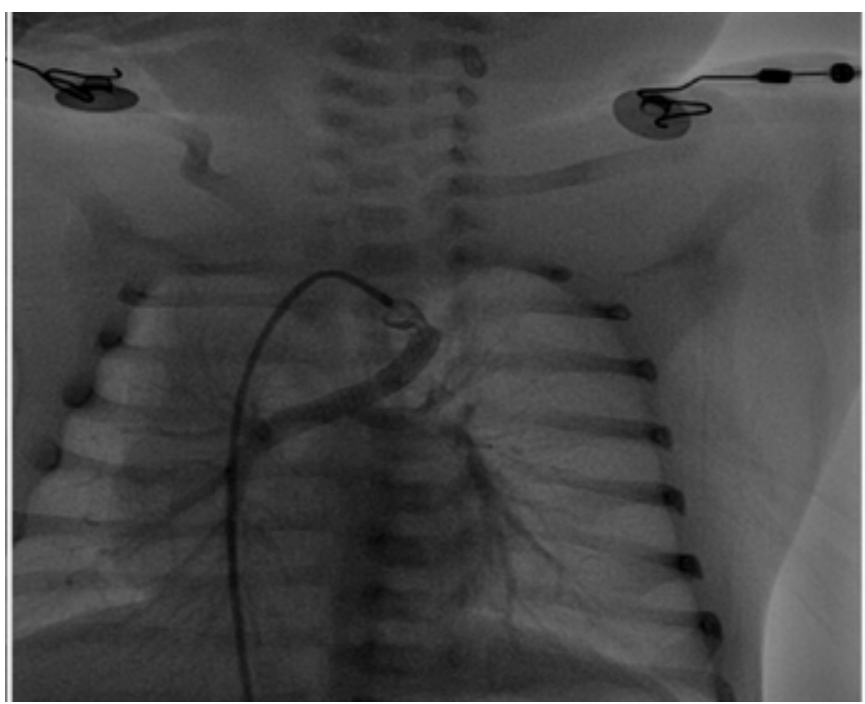


(Figure 1). Firstly distal narrowed part of ductus arteriosus was stented with a coronary stent $(4 \times 15 \mathrm{~mm})$ (Figure 2). After that a second coronary stent $(4 \times 15$ $\mathrm{mm}$ ) was implanted to cover most of the duct (Figure 3). The final oxygen saturation was $90 \%$ after two stent implantation. After cessation of prostaglandin infusion the patient' oxygen saturation gradually decreased up to the $55 \%$. Second cardiac catheterization

\section{Figure 5. Ductus arteriosus after three stent implantation}

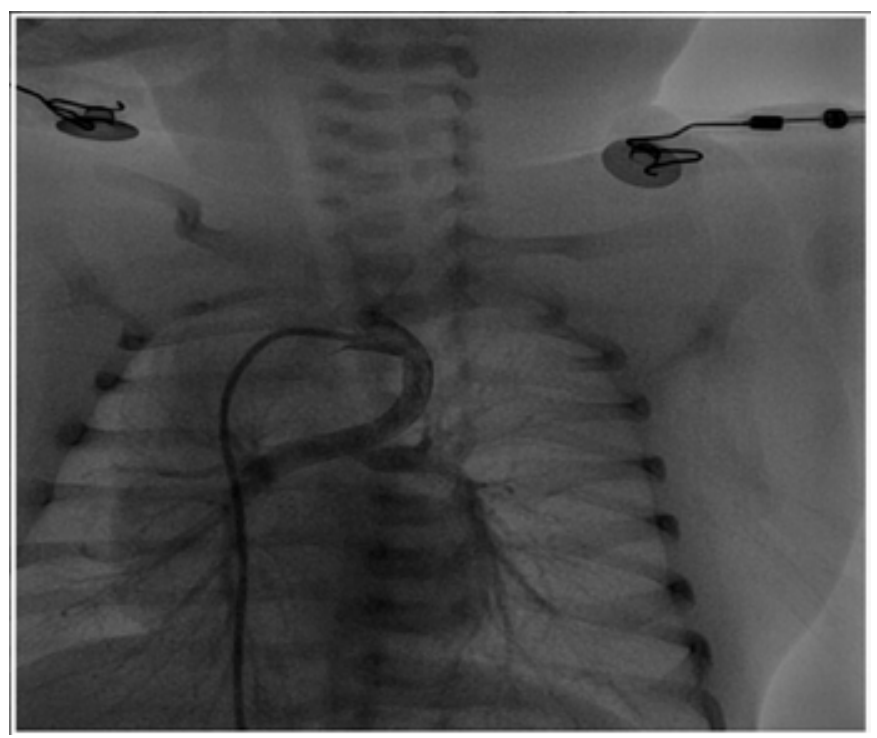

showed critically stenosis in aortic end of ductus (Figure 4). A third coronary stent $(4 \times 15 \mathrm{~mm})$ was placed to cover the aortic side entirely (Figure 5). The oxygen saturation was increased to $85 \%$ after third stent implantation. The patient was discharged with $\% 85$ oxygen saturation in the following days. During follow-up periods of to three months he had no problem clinically, weight gain and $\% 88$ percutaneous oxygen saturation.

\section{Discussion}

Ductal stenting a reliable and more physiologic alternative to surgical systemic to pulmonary shunt in neonates. But the lack of stent coverage of the entire ductus (especially in long and tortuous duct) results duct constriction and cyanosis of the patient and causes reintervention in most cases. It is well known that passing a catheter through the stent is technically very difficult and increases the risk of thrombosis and hemodynamic destabilization when compared with the primary intervention. Therefore stent long must be enough to cover entire ductus. But in some cases a small segment of the duct may be left uncovered and necessitating use of second or third stent. The full-length stenting of the duct without leaving any ductal tissue is important.

Received: 08/10/2016

Accepted: 25/02/2017

Published: 15/06/2017

Disclosure and conflicts of interest:

The authors declare no conflict of interest.

Corresponding author:

Dr. Tamer Yoldaş

Mail: tameryoldas@gmail.com 